\title{
NORTH AMERICAN TRILOBITE SPECIES DIVERSITY DURING THE LOWER PALEOZOIC
}

ADRAIN, Jonathan M., Dept. of Palaeontology, The Natural History Museum, Cromwell Road, London SW7 5BD, United Kingdom; WESTROP*, Stephen R., Dept. of Earth Sciences, Brock University, St. Catharines, Ontario L2S 3A1, Canada

In previous work, the diversity history of trilobites has generally been reconstructed from compilations of numbers of genera or higher taxa. from the published literature. Conventional wisdom holds that trilobite diversity increased steadily during the Cambrian to a maximum before the end of that period, with the subsequent history of the group involving a decline to complete extinction at the end of the Permian; reduction in diversity was particularly sharp at the end of the Ordovician and Devonian periods. Here, we present an evaluation of within-habitat (alpha) diversity during the Lower Paleozoic based upon species richness within collections of known sample size. Our data set consists of more than 100 collections that contain more than 30,000 trilobites. In order to document patterns of alpha diversity, the collections were divided into five broad enviromental groups: nearshore facies (coarse, shallow water siliclastics and peritidal carbonates), subtidal shales and storm deposits, subtidal, level-bottom carbonates, shelf carbonate buildups, and carbonate shelfmargin facies (the latter are represented by collections from shelf-margin derived debris flows and turbidites in slope sequences from Newfoundland and the Canadian Arctic). Preliminary results indicate that species richness remained at a roughly constant level between the Upper Cambrian and the Silurian in all environments for which we have data. This provides further support for the notion that the apparent decline in the importance of trilobites in paleocommunites during the Ordovician was a result of dilution as new clades radiated, rather than actual displacement. Through the Lower Paleozoic, peak diversity occurred in shelf-margin settings, with species richness per collection typically in the range of 25 to 50 species. Nearshore habitats, which are represented in our data set by Cambrian and Ordovician collections only, had the lowest diversity, with species richness ranging from one to six species. Although the Late Ordovician extinctions eliminated several major trilobite clades, it does not appear to have impacted greatly on species richness in the Silurian: Llandovery and Wenlock collections from all habitats for which we have data (subtidal shales and storm deposits; subtidal carbonates; carbonate buildups; shelf-margin carbonates) display levels of diversity comparable to those of the Ordovician. The primary decline in alpha diversity was a post-Silurian phenomenon in North America; preliminary data suggest that it occurred by the end of the Devonian, possibly, as others have suggested, in response to the initial mid-Paleozoic radiation of durophagous predators. 